ORNL/TM-2001/79

\title{
RESULTS OF THE ANALYSIS OF THE BLOOD BERYLLIUM LYMPHOCYTE PROLIFERATION TEST DATA FROM THE OAK RIDGE Y-12 STUDY
}

December 2001

\author{
Prepared by \\ E. L. Frome \\ D. L. Cragle \\ L. G Littlefield \\ S. P. Colyer
}




\section{DOCUMENT AVAILABILITY}

Reports produced after January 1, 1996, are generally available free via the U.S. Department of Energy (DOE) Information Bridge.

Web site http://www.osti.gov/bridge

Reports produced before January 1, 1996, may be purchased by members of the public from the following source.

National Technical Information Service

5285 Port Royal Road

Springfield, VA 22161

Telephone 703-605-6000 (1-800-553-6847)

TDD 703-487-4639

Fax 703-605-6900

E-mail info@ntis.fedworld.gov

Web site http://www.ntis.gov/support/ordernowabout.htm

Reports are available to DOE employees, DOE contractors, Energy Technology Data Exchange (ETDE) representatives, and International Nuclear Information System (INIS) representatives from the following source.

Office of Scientific and Technical Information

P.O. Box 62

Oak Ridge, TN 37831

Telephone 865-576-8401

Fax 865-576-5728

E-mail reports@adonis.osti.gov

Web site http://www.osti.gov/contact.html

This report was prepared as an account of work sponsored by an agency of the United States Government. Neither the United States nor any agency thereof, nor any of their employees, makes any warranty, express or implied, or assumes any legal liability or responsibility for the accuracy, completeness, or usefulness of any information, apparatus, product, or process disclosed, or represents that its use would not infringe privately owned rights. Reference herein to any specific commercial product, process, or service by trade name, trademark, manufacturer, or otherwise, does not necessarily constitute or imply its endorsement, recommendation, or favoring by the United States Government or any agency thereof. The views and opinions of authors expressed herein do not necessarily state or reflect those of the United States Government or any agency thereof. 


\title{
RESULTS OF THE ANALYSIS OF THE BLOOD BERYLLIUM LYMPHOCYTE PROLIFERATION TEST DATA FROM THE OAK RIDGE Y-12 STUDY
}

\author{
E. L. Frome \\ Computer Science and Mathematics Division \\ D. L. Cragle, L. G Littlefield, S. P. Colyer \\ Center for Epidemiologic Research \\ Oak Ridge Institute for Science and Education
}

Date Published: December 2001

\section{Prepared by}

OAK RIDGE NATIONAL LABORATORY

Oak Ridge, Tennessee 37831-6285

managed by

UT-Battelle, LLC

for the

U.S. DEPARTMENT OF ENERGY

under contract DE-AC05-00OR22725 


\section{Contents}

List of Figures

Abstract $\quad$ iv

1 INTRODUCTION

2 MATERIALS AND METHODS $\quad 3$

2.1 BERYLLIUM LYMPHOCYTE PROLIFERATION TEST $\ldots \ldots \ldots \ldots$

2.2 STATISTICAL ANALYSIS OF THE BELPT $\ldots \ldots \ldots \ldots \ldots \ldots$

2.3 IDENTIFICATION OF ABNORMAL BELPTS USING THE SBP METHOD . . . . . . . . 5

2.4 RECEIVER OPERATING CHARACTERISTIC (ROC) CURVE $\ldots \ldots \ldots$

3 RESULTS 6

3.1 GRAPHICAL RESULTS FOR MITOGEN CONTROL BELPT DATA $\ldots \ldots \ldots$

3.2 GRAPHICAL RESULTS FOR BERYLLIUM WORKERS AND CONTROLS $\ldots \ldots$

3.3 IDENTIFICATION OF ABNORMAL BELPTS USING THE SBP METHOD . . . . . . . . 8

3.4 IDENTIFICATION OF CASES AND ROC CURVE ANALYSIS . . . . . . . . . . . . 8

4 DISCUSSION 9

5 ACKNOWLEDGMENTS $\quad 19$

A APPENDIX $\quad 1$

A.1 LEAST ABSOLUTE VALUES ANALYSIS FOR BELPT $\ldots \ldots \ldots \ldots \ldots$

A.2 SUMMARY LAV REPORT FOR THE BELPT . . . . . . . . . . . . . . . . . . 4 


\section{List of Figures}

1 Histograms and Normal Q-Q Plots PHA: Log and Linear Scale . . . . . . . . . . . . . 11

2 Histograms and Normal Q-Q Plots ConA: Log and Linear Scale . . . . . . . . . . . . . 12

3 Histograms for SIs for Beryllium Workers and Nonexposed Controls . . . . . . . . . . . . 13

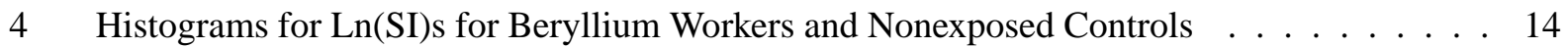

5 Normal q-q plots of $\operatorname{Ln}(\mathrm{si}) \mathrm{s}$ for beryllium workers and nonexposed $\ldots \ldots \ldots$

6 Histogram and Normal Q-Q Plot For $\operatorname{Ln}(\operatorname{SImax}) \ldots \ldots \ldots \ldots$

$7 \quad$ Boxplots and Normal Q-Q Plots For Maximum $\operatorname{Ln}(\mathrm{SI}) \ldots \ldots \ldots \ldots$

8 ROC Curves for Ln(SI)s for Beryllium "Cases" and Normal Individuals $\ldots \ldots$. . . . . . . 18 


\begin{abstract}
The potential hazards from exposure to beryllium or beryllium compounds in the workplace were first reported in the 1930s. The tritiated thymidine beryllium lymphocyte proliferation test (BeLPT) is an in vitro blood test that is widely used to screen beryllium exposed workers in the nuclear industry for sensitivity to beryllium. Newman [18] has discussed the clinical significance of the BeLPT and described a standard protocol that was developed in the late 1980s. Cell proliferation is measured by the incorporation of tritiated thymidine into dividing cells on two culture dates and using three concentrations of beryllium sulfate. Results are expressed as a "stimulation index" (SI) which is the ratio of the amount of tritiated thymidine (measured by beta counts) in the stimulated cells divided by the counts for the unstimulated cells on the same culture day. Several statistical methods for use in the routine analysis of the BeLPT were considered in the early 1990's by Frome et al. [7]. The least absolute values (LAV) method was recommended for routine analysis of the BeLPT. The purposes of this report are to further evaluate the LAV method using new data, and to describe a new method for identification of an abnormal or borderline test. This new statisticalbiological positive (SBP) method reflects the clinical judgment that i) at least two SIs show a "positive" response to beryllium, and ii), that the maximum of the six SIs must exceed a cut point that is determined from a reference data set of normal individuals whose blood has been tested by the same method in the same serum. The new data is from the Y-12 facility in Oak Ridge and consist of 1080 worker and 33 nonexposed control BeLPTs (all tested in the same serum). Graphical results are presented to explain the statistical method, and the new SBP method is applied to the Y-12 group. The true positive rate and specificity of the new method were estimated to be 86 percent and 97 percent, respectively.

The Department of Energy (DOE) has developed DOE-SPEC-1142-2001:BERYLLIUM LYMPHOCYTE PROLIFERATION TESTING [24] that describes the laboratory procedure and statistical analysis based on the SBP method for use in the BeLPT. DOE-SPEC-1142-2001 and the review process that was used to provide comments and improvements are available in an "electronic notebook". The electronic notebook Notes Concerning the Tritiated Thymidine Beryllium Lymphocyte Proliferation Test (BeLPT-NB) can be accessed via the Internet at http://www.csm.ornl.gov/ frome/BE/tnote.html.
\end{abstract}




\section{INTRODUCTION}

The potential hazards of exposure to beryllium compounds were first reported in the 1930s. The clinical syndrome of chronic beryllium disease (CBD) ${ }^{1}$ was first described by Hardy and Tabershaw in 1946 [10]. Initial speculation on the immunologic basis of chronic beryllium disease (CBD) occurred in the 1950s [20]. The first in vitro observation of beryllium-specific cell proliferation was demonstrated in 1970 [9]. CBD mainly affects the lung, and occurs in a small percentage of persons exposed to beryllium dusts. Most clinicians rely on evidence of beryllium hypersensitivity as one of several criteria for diagnosis of the disease. In vitro proliferation of lung lymphocytes retrieved by bronchoalveolar lavage and exposed to beryllium is extremely sensitive to and specific for the diagnosis of CBD, but is not suitable for screening since cell retrieval is an invasive procedure-see Stokes and Rossman [21]. A less invasive procedure based on the proliferative response of blood cells to beryllium has been developed and is referred to as the blood beryllium lymphocyte proliferation test (BeLPT). Newman [17] has noted that lymphocytes isolated from a lung lavage or peripheral blood of CBD patients show an in vitro response to beryllium stimulation that distinguishes CBD from other granulomatous lung diseases such as sarcoidosis. The BeLPT was first used as a clinical diagnostic tool in the 1980s, and the tritiated thymidine BeLPT as used today was further developed in the late 1980s. The historical development and significance of the tritiated thymidine BeLPT in identification of beryllium sensitization and CBD was reviewed by Newman at a conference on Beryllium-related diseases in 1994 [18]. Kreiss et al. [12] provide a review of epidemiologic and experimental work related to CBD and noted that the laboratories that perform the BeLPT have formed a working group (CABST, Committee to Accredit Beryllium Sensitivity Testing) to resolve technical problems related to the test. Beryllium has been used in the nuclear industry for a number of years. Kreiss et al. [14] have examined the epidemiology of CBD in a stratified sample of workers at a nuclear weapons plant and discuss the role of the BeLPT in beryllium disease surveillance in the nuclear industry. The U.S. Department of Energy (DOE) is operating a screening program for CBD that will eventually include approximately 30,000 current and former beryllium-exposed workers at 20 DOE sites. The use of beryllium in several new economic sectors emphasizes the need for medical surveillance in the workplace for CBD, see e.g. Kreiss et al. [13].

Methods used in the calculation of BeLPT test results are important since it is the primary test that is used in large population screening and surveillance for CBD. The BeLPT relies on replicate measurements for each calculated value (12 replicates for control values and 4 replicates for beryllium-stimulated values).

\footnotetext{
${ }^{1}$ Abbreviations used: AB, abnormal; AUC, area under the curve; Be, beryllium; BeLPT, beryllium lymphocyte proliferation test; CABST, Committee to Accredit Beryllium Sensitivity Testing; CBD, chronic beryllium disease; ConA, concanavalin-A; CV, coefficient of variation; df, degrees of freedom; FPP, false positive probability; FPR, false positive rate; LAV, least absolute values; LPT, lymphocyte proliferation test; MAD, median absolute deviation; ORISE, Oak Ridge Institute for Science and Education; ORNL, Oak Ridge National Laboratory; PHA, phytohemagglutinin; q-q, quantile-quantile; ROC; receiver operating characteristic; SI, stimulation index; SLsi, standardized $\mathrm{Ln}(\mathrm{SI})$; TPR, true positive rate.
} 
In response to concerns over the effect of "outliers" in the BeLPT data, a new statistical approach was developed and presented at the 1994 conference by Frome et al. [7]. Two outlier-resistant methods were used to estimate the stimulation indices (SIs) and the coefficient of variation. A major advantage of these resistant methods is that they make it unnecessary to identify outlying data values among the replicate well counts. The method that was recommended by Frome et al. [7] for routine analysis of the BeLPT uses the least absolute values (LAV) method on the Ln of the replicate counts. This new LAV method was developed on a small data base from the lymphocyte proliferation test (LPT) laboratory at Oak Ridge Institute for Science and Education (ORISE). It was presented to CABST in April 1994, and further evaluation of the LAV method at another laboratory was requested. The LAV method was further "field tested" using data from the LPT laboratory at the National Jewish Medical and Research Center (NJC). The results of this evaluation supported the earlier conclusion that the LAV method is a simple and effective method that requires less judgment for routine analysis of the BeLPT (see Frome, Newman and Mroz [6]), and was included in the protocol for BeLPT testing that was being developed by CABST.

In the standard protocol for the BeLPT a stimulation index (SI) is calculated for each of three beryllium concentrations on two harvest days. Once SIs have been calculated it is necessary to determine if the results indicate an "abnormal" response to beryllium. Three methods were considered in previous reports that utilize a "cut point" established using a reference data base of BeLPTs (see Frome et al. [7],[6]). A set of BeLPTs performed as part of a study of workers at the Y-12 plant in Oak Ridge is used here to further evaluate the LAV method, and the procedure for identifying an abnormal test. The purpose of the Y-12 study [3] was to examine the workplace characteristics of individuals sensitized to beryllium within a research cohort of 1,151 current and retired workers enrolled in a medical examination program. Results presented here are limited to BeLPTs for workers and controls $(\mathrm{N}=1113)$ that were done in the same lot of ABi Serum (3040083) as part of the Y-12 study, and only the first test in this serum is included if a worker had more than one test. If a worker's first test was considered abnormal or borderline and a repeat test was done in the same serum, only the first test was included. This serum was used in over 97 percent ( $\mathrm{N}=1080)$ of the BeLPTs in the Y-12 study, and 33 nonexposed (control) BeLPTs. A draft report was completed in November of 1999 and the results were presented to the ORISE Beryllium Advisory Committee (http://www.csm.ornl.gov/ ${ }^{\sim}$ frome/vgLPT/TTLPT/ ${ }^{2}$ ). The results in this draft report were based on summary statistics computed by the ORISE LPT laboratory. The first objective of the draft report was to present graphical summaries - using histograms and normal quantile-quantile (q-q) plots—of the SIs in original units and in logarithmic units to verify the assumption that the variability in SIs is best described by the normal distribution on a logarithmic scale, i.e. a lognormal distribution. A detailed account of the construc-

\footnotetext{
${ }^{2}$ See view-graphs and draft Y-12 report with results of methods 1 and 2 at this URL
} 
tion and interpretation of normal q-q plots (also called normal probability plots) is provided by Chambers et al. [2]. The second objective of the draft report was to compare two previously described methods for the identification of an abnormal test.

In July of 2000 DOE decided that a Specification for the BeLPT was needed to support the worker surveillance programs. A working group was established to write an initial draft version of the BeLPT Specification, and an electronic notebook (see Geist and Nachtigal [8]) was used to document the development, review, and revision of the BeLPT Specification-see [5] BeLPT-NB [4]. A draft protocol was provided to DOE by CABST, and the initial draft Specification was completed in September, 2000, and sent to an expert review panel (see pages 9 and 10 of the BeLPT-NB [4]). Comments on the initial draft are provided on pages 13 - 19 of the BeLPT-NB, and a revised draft was submitted for further review in January, 2001 (see BeLPT-NB page 20). The final version of the specification was completed in April, 2001 [24] and is available on page 21 of the BeLPT-NB [4].

The two methods considered in the draft version of this report were based on "cut points" that were calculated from the $\mathrm{Ln}(\mathrm{SI}) \mathrm{s}$ in the reference data set, and the internal variability in each test was not taken into consideration. These methods for identification of an abnormal BeLPT were considered unacceptable by the working group for either statistical or practical reasons. A new method is proposed that combines clinical judgment and statistical analysis to identify an abnormal test or an individual that needs a closer level of monitoring in the future. This new method described in Section 2.3 is refered to as the statisticalbiological positive (SBP) method. The SBP method requires estimates of standardized $\mathrm{Ln}(\mathrm{SI}) \mathrm{s}$ and these values are best computed from the raw data for each BeLPT. Only a portion of the raw data sets were available during the initial development of the SBP method, so estimates based on summary statistics were used in the draft Y-12 report. In December 2000 the raw data for all of the 1113 BeLPTs (1080 workers and 33 controls) were obtained in electronic form and are used in this report. For this reason the results in this report may differ slightly from the initial results in the draft Y-12 report that appear in the BeLPT-NBFrome and Cragle [4] see page 7.

\section{MATERIALS AND METHODS}

\subsection{BERYLLIUM LYMPHOCYTE PROLIFERATION TEST}

The tritiated thymidine BeLPT has followed a standard protocol for laboratory procedure and data collection since the late 1980s. A detailed description of lymphocyte culture methods, quality control measures, and examples of plate maps and printouts of raw data in use at the ORISE BeLPT laboratory was provided by Frome et al. [7]. This and several alternative assay designs are described in the BeLPT-NB[4]—see pages 2-5. The details of the procedure and the equipment used vary at different laboratories and the essential 
requirements are described in DOE-SPEC-1142-2001 [24]. The ORISE protocol is briefly summarized as follows:

1. A $30 \mathrm{ml}$ blood sample is obtained from each patient using sodium heparin as an anticoagulant. The mononuclear cells are separated using density gradient and centrifugation.

2. Lymphocytes are cultured using standard methods at a final concentration of $2.5 \times 10^{5}$ cells per well in 96-well flat-bottom microtiter plates. For each BeLPT assay 12 replicate control wells, and four replicates for each beryllium concentration (i.e., 1, 10, and $100 \mu \mathrm{M}$ of $\mathrm{BeSO}_{4}$ ) are set up in duplicate and harvested after five and seven days of incubation, respectively. Mitogen-stimulated controls are also set up to test the cells ability to grow in culture.

3. Cells are incubated at $37^{\circ} \mathrm{C}$ for five and seven days and a pulse of tritiated thymidine is delivered prior to harvest. Cells are harvested on filter paper and counts are measured in a Packard Matrix 96 gas ionization counter. Each filter is counted for 10 minutes and the results organized as shown in Exhibit A1 in the Appendix for statistical analysis.

\subsection{STATISTICAL ANALYSIS OF THE BELPT}

As the result of biological variability in the well counts there are different levels of uncertainty present in each BeLPT. This internal variability is described by the standard deviation of the Ln well counts, and is equivalent to the coefficient of variation on the original scale. This "internal analysis" of the BeLPT is based on estimates of the $\operatorname{Ln}(\mathrm{SI}) \mathrm{s}$ and their standard errors. These estimates are calculated using the least absolute values (LAV) method as described by Frome et al. [7]. This approach only requires the ability to calculate medians and can be done in a spread sheet (e.g., Excel, see page 14 of the BeLPT-NB [4]) or statistical program (e.g., Splus or R). The LAV analysis is based on the assumptions that:

1. the Ln of the well counts follow the normal distribution;

2. standard deviations of Ln counts are constant within harvest days;

3. multiple outliers may be present in the Ln well counts; and

4. if "responder cells" are present, an increase in cell proliferation relative to the control wells will occur in cultures with beryllium.

The detailed calculations for the LAV analysis are provided in the Appendix with an example. The steps in the analysis are summarized as follows: 
1. Calculate the Ln of the well counts.

2. For each "treatment group" calculate the median of the Ln counts.

3. For each beryllium concentration, calculate the $\operatorname{Ln}(\mathrm{SI})$ by subtracting the median of the the control well Ln counts from the median of the Be stimulated Ln counts.

4. Calculate the standard error of each $\operatorname{Ln}(\mathrm{SI})$.

5. Calculate the standardized $\operatorname{Ln}(\mathrm{SI}): \mathrm{SLsi}=\mathrm{Ln}(\mathrm{SI}) / \mathrm{StErr}[\log (\mathrm{SI})]$.

\subsection{IDENTIFICATION OF ABNORMAL BELPTS USING THE SBP METHOD}

This new SBP method reflects the clinical judgment that i) at least two sets of beryllium stimulated wells should show a positive response, and ii) the requirement that the maximum SI must exceed a cut point that is determined from a reference data set of normal individuals. A BeLPT is considered abnormal if both the following statistical and biological criteria are satisfied.

1. Statistical analysis of the BeLPT indicates a positive response to beryllium. A positive response to beryllium occurs if at least two SLsis are greater than 2.53. This is refered to as a "statistical positive" test and has a false positive probability (FPP) of about 0.001 (see Appendix for details).

2. The $\log$ of the maximum SI—Ln(SImax)—exceeds the 99.9th percentile of a Reference Data Set (RDS), indicating a positive response to beryllium, with a FPP of 0.001. This is called a "biological positive" test since it is based on the distribution of the $\operatorname{Ln}(\operatorname{SImax})$ values in the RDS of normal tests. The $\operatorname{Ln}(\operatorname{SImax})$ values for the RDS are assumed to follow the normal distribution with location parameter $\mathrm{M}$ and scale parameter $\mathrm{S}$. The 99.9 percentile cut point is estimated as $\mathrm{Cp} 99.9=\mathrm{M}+$ $3.09 * \mathrm{~S}$, where $\mathrm{M}$ and $\mathrm{S}$ are estimated from the RDS of normal BeLPTs. An equivalent evaluation is to calculate the metric $\mathrm{Zmax}=[\operatorname{Ln}(\operatorname{SImax})-\mathrm{M}] / \mathrm{S}$ and determine if it is greater than 3.09 , which is the 99.9 percentile of the standard normal distribution.

If only one of these criteria is met, and the data is otherwise acceptable, then the test is considered to be a "borderline" test. If neither criteria is met the test is normal. If a patient's first test is not normal a second evaluation is requested, and two repeat BeLPTs are done in different laboratories or in the same laboratory using different sera. If at least two of the three BeLPTs are abnormal the patient is deemed beryllium sensitized. Since the criteria for a single abnormal BeLPT is based on an approximate false positive probability of 0.001 , the chance of calling a person a "sensitized responder" is very small (less than one in ten thousand). This is based on the assumption that all nonexposed individuals will show a normal response to beryllium. In practice it is known that some individuals with no known exposure to beryllium will have an abnormal BeLPT. These are referred to as "biological false positives" (see page 6 
of the BeLPT-NB[4] for a detailed discussion of a biological as opposed to statistical false positive test and related statistical issues). Consequently, the observed FPR will be higher than expected based on statistical considerations alone. A person may be a "sensitized responder" and not have CBD. If a person is identified as sensitized, then further medical evaluation is available to determine if the worker has CBD—see, e.g. Stokes and Rossman [21] for details.

\subsection{RECEIVER OPERATING CHARACTERISTIC (ROC) CURVE}

The second criteria in Section 2.3 is based on results obtained using a single cut-point $\left(c_{p}\right)$ for a biological positive test. The ROC curve is a graphical tool that has been developed to evaluate the accuracy of a diagnostic test when the test result is on a continuous scale, i.e $\mathrm{Ln}(\mathrm{SI}) \mathrm{s}$, by considering all possible cutpoints—see Swets and Pickett [22]. Stokes and Rossman [21] considered ROC analysis in beryllium testing and Zou and Zhou [25] provide a recent review. A nonparametric estimate, see e.g. Lloyd [15], of the ROC curve is obtained by plotting the empirical proportion $\# L_{1 i} s>c_{p} / n_{1}$ against $\# L_{0 i} s>c_{p} / n_{0}$ for varying $c_{p}$. The $L_{1 i} s$ are the $\mathrm{Ln}(\mathrm{SI}) \mathrm{s}$ for those individuals that are "cases" (i.e. they are sensitized and/or have CBD) and $L_{0 i}$ are the $\mathrm{Ln}(\mathrm{SI}) \mathrm{s}$ for the normal individuals. The values on the vertical axis of the ROC curve are estimates of the true positive rate (TPR), and the horizontal axis values estimate the false positive rate (FPR) for each cut-point. The case status of each worker was not know at the time the test was done and was established by following the group of Y-12 workers for five years as described in Section 3.4. In ROC analysis the area under the curve (AUC) is considered as an overall "index of accuracy", see e.g. Swets and Pickett (chap. 1)[22] of a test. Pepe [19] consider the partial AUC as an alternative summary measure of accuracy. It has been argued that a FPR above some threshold would not be used in practice and, therefore, the ROC curve is of no interest beyond this point. If $c_{o}$ is the largest FPR of practical interest, then the partial AUC is the area under the ROC curve over the subinterval $\left(0, c_{o}\right)$. In the results $c_{o}=0.05$ is used to calculate a summary measure over a practically relevant range of operating points for the BeLPT. A consistent nonparemetric estimate of the partial AUC is obtained using the method described by Pepe [19].

\section{RESULTS}

\subsection{GRAPHICAL RESULTS FOR MITOGEN CONTROL BELPT DATA}

In the ORISE protocol each BeLPT includes two sets of four wells for the mitogen controls-concanavalin$\mathrm{A}(\mathrm{ConA})$ and phytohemagglutinin(PHA). Graphical summaries of the mitogen control SIs for 1113 BeLPTs are shown in Fig. 1 and Fig. 2. In a normal q-q plot, if the relation between the empirical quantiles (on the vertical axis) and theoretical quantiles (on the horizontal axis) is linear, this indicates that the data are 
described by a Qaussian (normal) distribution. Each figure displays the data in a histogram (left panel) and a normal q-q plot (right panel). The upper panels show SIs after a natural log (Ln) transformations and the lower panels are untransformed SIs. In both figures the normal q-q plots for the Ln(SI)s (see top right panels in Fig. 1 and 2.) strongly support the use of the lognormal distribution to describe the variation in the SIs when the agent is strongly mitotic. The only departure from the lognormal distribution is in the lower tail. This is due to the mitogen stimulated cultures being well past the peak of their growth curve. If there is a strong mitotic response, and cell overgrowth occurs, the SI may be artifically low. If this occurs the wells have a distinct yellow appearance that indicates the presence of dead cells as the result of depletion of cell nutrient from the growth medium. In over 6000 tests the ORISE LPT laboratory has not encountered a single BeLPT in which the mitogen controls failed to show a response.

\subsection{GRAPHICAL RESULTS FOR BERYLLIUM WORKERS AND CONTROLS}

Histograms for the SIs for each harvest day and Be concentration for the BeLPT data are shown in Fig. 3 (data from beryllium workers and nonexposed controls are combined). For the serum supplement used in this study SIs above three were abnormally high, indicating a response to beryllium. For plotting purposes SIs greater than four have been set equal to four. Figure 4 shows the histograms for the $\operatorname{Ln}(\mathrm{SI}) \mathrm{s}$ for the same data. Comparing the histograms in Fig. 3 and 4 indicates that the SIs are best described by the normal distribution on the log scale. This is further supported by Fig. 5 which shows lognormal probability plots for the beryllium workers and nonexposed control SIs for each of the three beryllium concentrations on day 5 and day 7. In each of the six plots the data—ordered values of the $\operatorname{Ln}(\mathrm{SI}) \mathrm{s}$ - are shown on the vertical scale on the left, and the quantiles of the standard normal distribution are shown on the horizontal scale. Each plot includes the median (labeled M) and the MAD estimate of the standard deviation (labeled S) for the $\operatorname{Ln}(\mathrm{SI}) \mathrm{s}$ for the beryllium workers (shown as circles) and the nonexposed $\log (\mathrm{SI}) \mathrm{s}$ (shown as triangles.) The lines in each plot (solid for nonexposed and dotted for beryllium workers) show the relation that is expected if the $\mathrm{Ln}(\mathrm{SI})$ values are from a normal distribution with location parameter $\mathrm{M}$ (which determines the intercept) and standard deviation $\mathrm{S}$ (which determines the slope).

Figure 5 reflects the assumption that most beryllium exposed workers do not show an abnormal response, i.e. they look like the nonexposed group. The relation between the empirical quantiles and theoretical quantiles is approximately linear in the center of the distribution indicating that the distribution is Gaussian. For example, consider the plot for day $5 \mathrm{Be}-1$ in Fig. 5. The $\mathrm{Ln}(\mathrm{SI}) \mathrm{s}$ appear to be approximately normal in the center, for both the nonexposed controls and the beryllium workers. There are several values that are larger than expected (these are the points above the lines). These "outliers" are SIs that indicate hypersensitivity to beryllium. There are also several points below the line which indicate cell killing. The effect of outliers 
on these estimates has been minimized since resistant methods were used to estimate the location and scale parameters, $\mathrm{M}$ and S, respectively. The results in Fig. 5 are similar to plots for previous ORISE data—see [7] Fig. 5, and similar BeLPT test results from The National Jewish Center-see [6] Figs. 5 and 6.

\subsection{IDENTIFICATION OF ABNORMAL BELPTS USING THE SBP METHOD}

The SBP method described in Section 2.3 was used to evaluate each BeLPT. The first step was to calculate the SLsi for each beryllium concentration on Day 5 and Day 7 (see line 3 of Appendix II for an example). If at least two of the SLsis are greater than 2.53 then the test is a statistical positive. The example in the Appendix has two SLsis greater than 2.53 so it is considered a statistical positive test. The second step requires estimates of the location and scale parameters for the RDS. The BeLPTs from the nonexposed controls were used as the RDS. The Ln(SImax) values for the nonexposed controls and beryllium workers are shown in box plots (left panel) and normal q-q plots (right panel) of Fig. 7. A detailed example and explanation of boxplots and q-q plots is provided in the BeLPT-NB (see "click here for details" in Item 1 on page 7). The $\operatorname{Ln}(\operatorname{SImax})$ for the nonexposed controls appear linear and the Kolmogorov-Smirnov test indicates that the lognormal distribution cannot be rejected. The q-q plot for the beryllium workers shows that most of the test results are described by the same lognormal model, but there are a number of tests that have $\operatorname{Ln}(\operatorname{SImax})$ values that are either too large (positive test) or too small (as the result of cell killing). This is further supported by the fact that the outlier resistant estimates of the lognormal scale(M) and location(S) parameters for the nonexposed data are almost identical to those for the beryllium workers data. The estimate of $\mathrm{M}$ from the RDS is 0.0812 and the estimate of $\mathrm{S}$ is 0.34 . A biological positive test occurs (see criterion 2 in Section 2.3) if $\mathrm{Zmax}=[\operatorname{Ln}(\operatorname{SImax})-\mathrm{M}] / \mathrm{S}$ is greater than 3.09. For the example in the Appendix $\mathrm{Zmax}=$ [ $0.98-0.0812] / 0.34=2.64$, indicating that this is not a biological positive test. Consequently, the example is considered a "borderline" test, and two additional BeLPTs were obtained for this worker. Both of these were abnormal so the worker is considered sensitized to beryllium as described in Section 2.3.

\subsection{IDENTIFICATION OF CASES AND ROC CURVE ANALYSIS}

All of the BeLPTs in the Y-12 group were done before July, 1996, and all of the workers with a positive test and most of the 944 workers with an initial normal test were followed and re-tested over the next five years. The results of this follow-up are shown in Columns 2-7 of Table 1. A total of 132 BeLPTs had an initial positive test by at least one of the criteria in Section 2.3. There were 80 BeLPTs that were abnormal, 38 tests with Zmax greater than 3.09 (biological positive only), 16 tests with at least two SLsis greater than 2.53 (statistical positive only), and 948 normal tests. These groups are identified in the first column of Table

\section{The classification of individuals in the columns 2-6 of Table 1 was based on the criteria being used}


by the ORISE LPT laboratory at the time the tests were done (not the criteria in Section 2.3). A worker was classified as sensitized (SENS) if an initial test was repeated twice and at least two of the three results were abnormal. A BeLPT was abnormal (A) if at least two SIs exceeded a cut point of 2.42. This cut point was calculated using the SImax for each BeLPT in the RDS, and is equal to the mean $+2 *(\operatorname{standard}$ deviation). The mean SImax was 1.27 and the standard deviation was 0.576. A test was borderline (B) if only one SI exceeded the cut point, and the data was otherwise acceptable. If only one BeLPT was done the follow-up status is unknown (Un). If a worker was identified as sensitized, then further medical evaluation was available. If a sensitized worker was evaluated clinically and diagnosed with CBD they are in column 6 of Table 1, otherwise they are in column 5. If a sensitized worker did not have a clinical evaluation their CBD status is not known and they are included in column 5. If a worker was neither abnormal or normal they are considered borderline and further monitoring is indicated. A worker would be in this classification if, for example, they had an initial abnormal BeLPT, and the split tests were borderline and normal.

The results of the SPP method summarized in Table 1 can be used to estimate the true positive rate (TPR) and false positive rate (FPR) for a first abnormal BeLPT in a specific serum. The results in Table 1 were further summarized by assuming that i) individuals follow-up status reflects their condition at the time the first test was done; ii) individuals with unknown status were normal (these are mostly retired workers with a normal first test that are asymptomatic); iii) individuals that have CBD are sensitized; and iv) individuals that were not sensitized to beryllium are normal. The TPR of the first BeLPT in Serum 3040083 is 48/56 or 85.7 percent, and the specificity(1-FPR) is 992/1024 or 96.9 percent. The ORISE LPT laboratory identified abnormal BeLPTs using the methods and criteria in place at the time that each test was done. Using the information from the ORISE historical data base the TPR was 78.6 percent and the specificity was 98.3 percent. If individuals with unknown status (see ii above) are not included in the calculations, then the specificity for the SBP method is 96.0 percent, and the specificity for ORISE historical method is 92.7 percent.

Table 1 is based on results obtained using a single cut-point $\left(c_{p}\right)$ for a biological positive test as described in Section 2.3. The ROC curves for each harvest day and beryllium concentration are shown in Fig. 8. The AUC and the partial AUC over the interval $(0,0.05)$ are given for each curve (see Section 2.4).

\section{DISCUSSION}

The graphical results in Figs. 1-7 of Section 3 provide empirical evidence that the assumptions described in Section 2.2 are reasonable. The results in Table 1 indicate that the SBP method, using the LAV approach to estimate the SIs, is at least as good as current methods for evaluating the BeLPT. The "outlier rejection method" that is used by some laboratories has no logical statistical basis (see page 16 of the BeLPT-NB 
Table 1 Summary Follow-Up Data For Y-12 Group

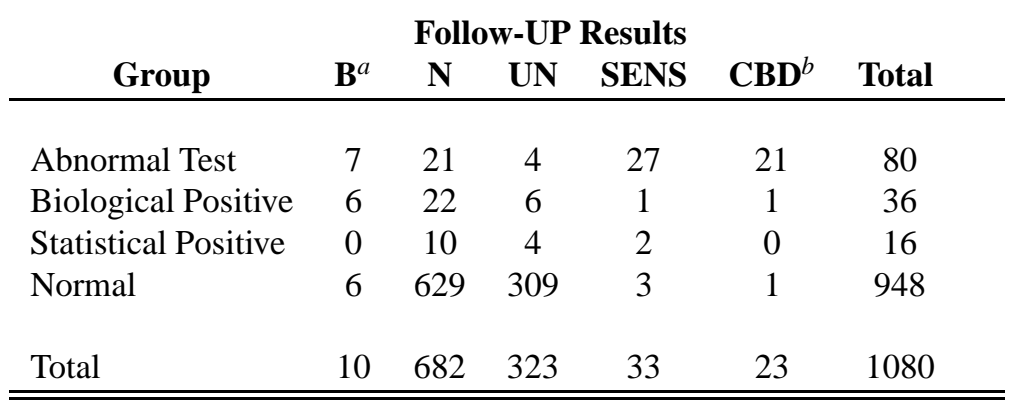

${ }^{a}$ B-Borderline N-Normal Un-Unknown SENS-sensitized

${ }^{b} \mathrm{CB}$ see Section 2.3 for explanation.

notebook [4] for further discussion). Further evaluation of this approach is currently underway using results from ORISE obtained in several different sera after 1996, and using data from at least two additional laboratories. The results of this work and any additional information related to the tritiated thymidine BeLPT will be added to the BeLPT-NB.

The ROC analysis in Fig. 8 indicates that results on Day 5 are generally more accurate than Day 7 and that the $10 \mu \mathrm{M} \mathrm{BeSO}_{4}$ challenge provides the best result on both days. A possible verification bias occurs since all workers with a normal first test do not receive additional tests during follow-up. This problem primarily occurs in the group of retired workers with a normal first test that are asymptomatic. Active workers in the beryllium surveillance program were re-tested on a regular basis. For this ROC analysis it is assumed that retired workers that are asymptomatic would be normal in subsequent testing for this analysis. The "gold standard" used to identify "cases" is therefore imperfect, since a worker is considered "sensitized" to beryllium if they have at least two abnormal BeLPTs, i.e. clinical verification of CBD status is optional—see Zou and Zhou [25] for further discussion. 


\section{Y-12 Beryllium Workers Study (Serum 2): Results For PHA}

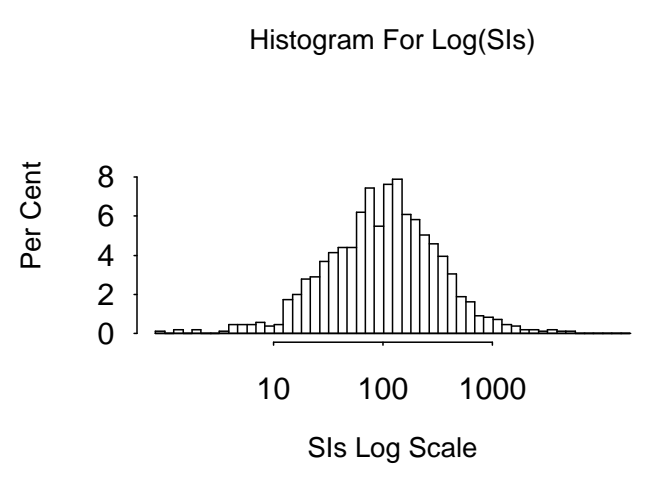

Histogram For SI

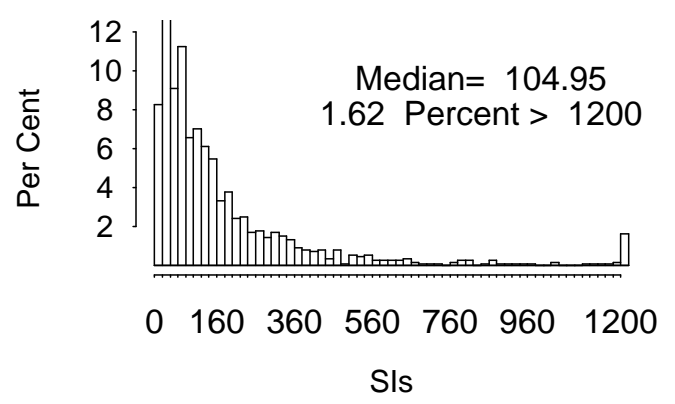

Log-Normal Quantile-Quantile Plot

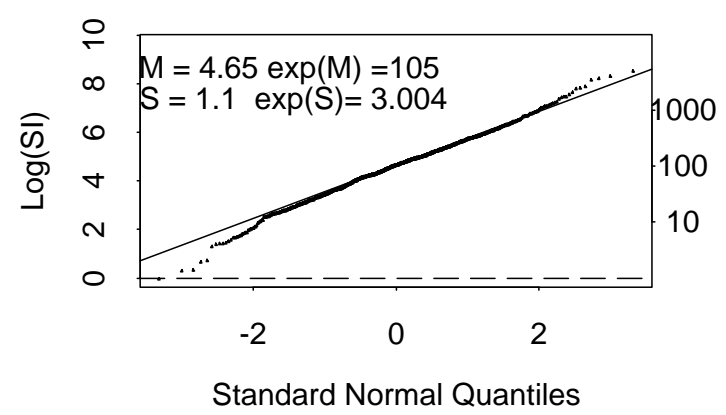

Normal Quantile-Quantile Plot

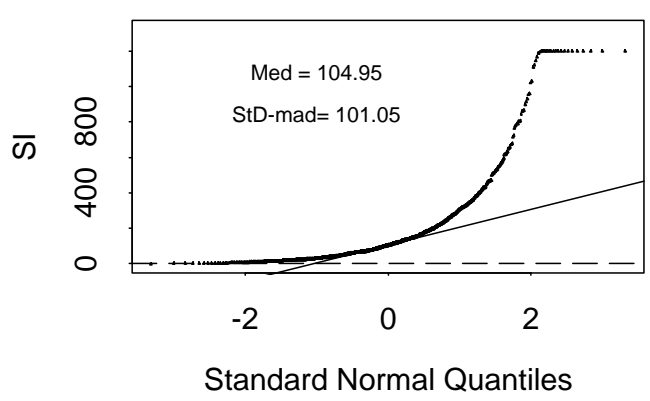

NOTE: In Bottom Panels Sls Greater Than 1200 Replaced with 1200

Fig. 1. The panels on the left show the histograms of the SIs. The top left is for $\operatorname{Ln}(\mathrm{SI}) \mathrm{s}$ and the bottom left is for the SIs. The panels on the right are normal q-q plots. If the data in the histogram (on the left) is normally distributed then the normal q-q plot (on the right) should look like a straight line. These plots clearly show that $\operatorname{Ln}(\mathrm{SI})$ s follow the normal distribution, i.e. the SIs follow the lognormal distribution. 
Y-12 Beryllium Workers Study (Serum 2): Results For CONA
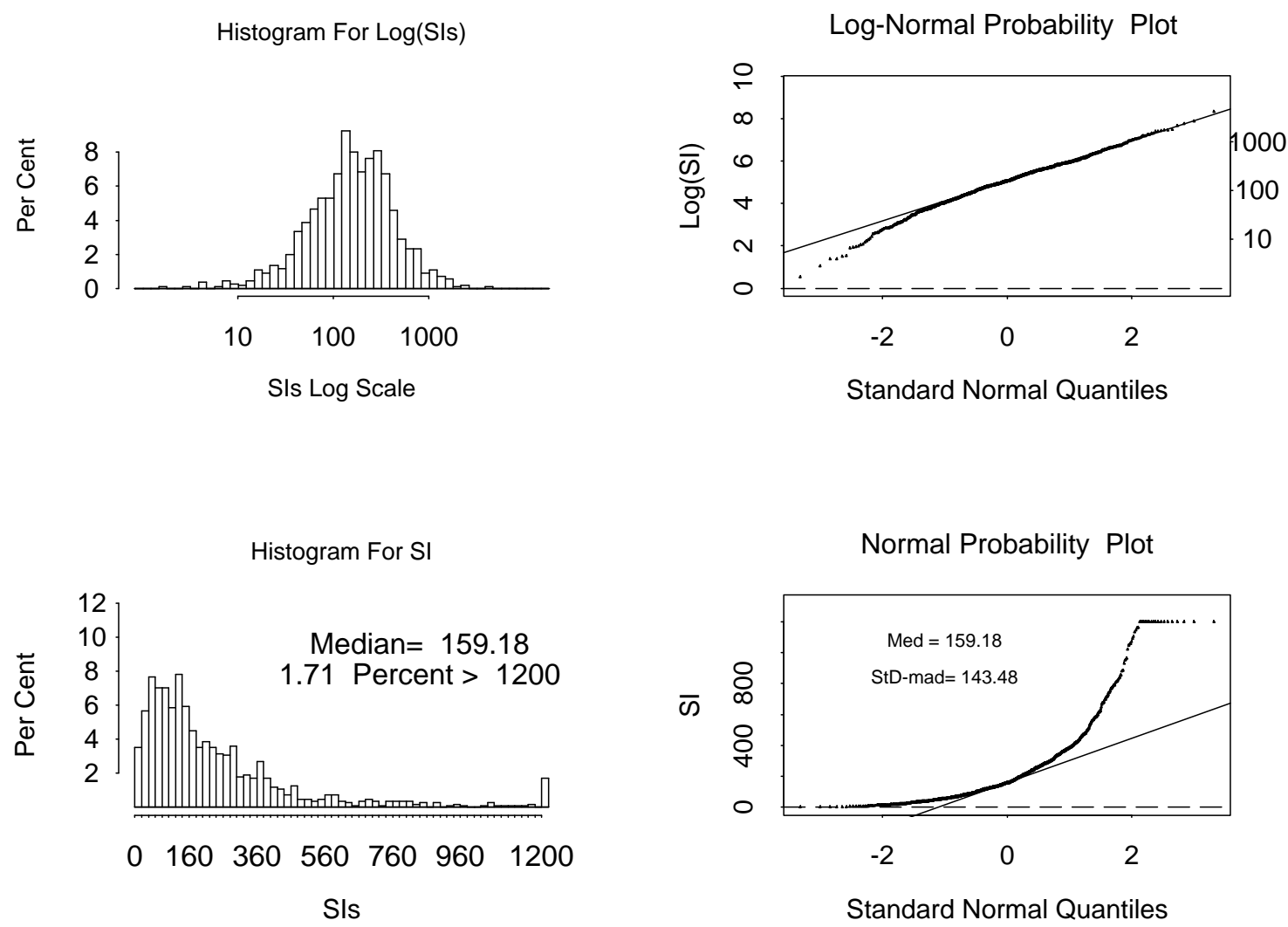

NOTE: In Bottom Panels Sls Greater Than 1200 Replaced with 1200

Fig. 2. The panels on the left show the histograms of the SIs. The top left is for $\operatorname{Ln}(\mathrm{SI}) \mathrm{s}$ and the bottom left is for the SIs. The panels on the right are normal q-q plots. If the data in the histogram (on the left) is normally distributed the the probability plot (on the right) should look like a straight line. These plots clearly show that $\mathrm{Ln}(\mathrm{SI}) \mathrm{s}$ follow the normal distribution, i.e. the SIs follow the lognormal distribution. 
Y-12 Study: BeLPTs In Serum 2 For 1080 BWs and 33 NEs SIs Greater Than 4 Set Equal To 4
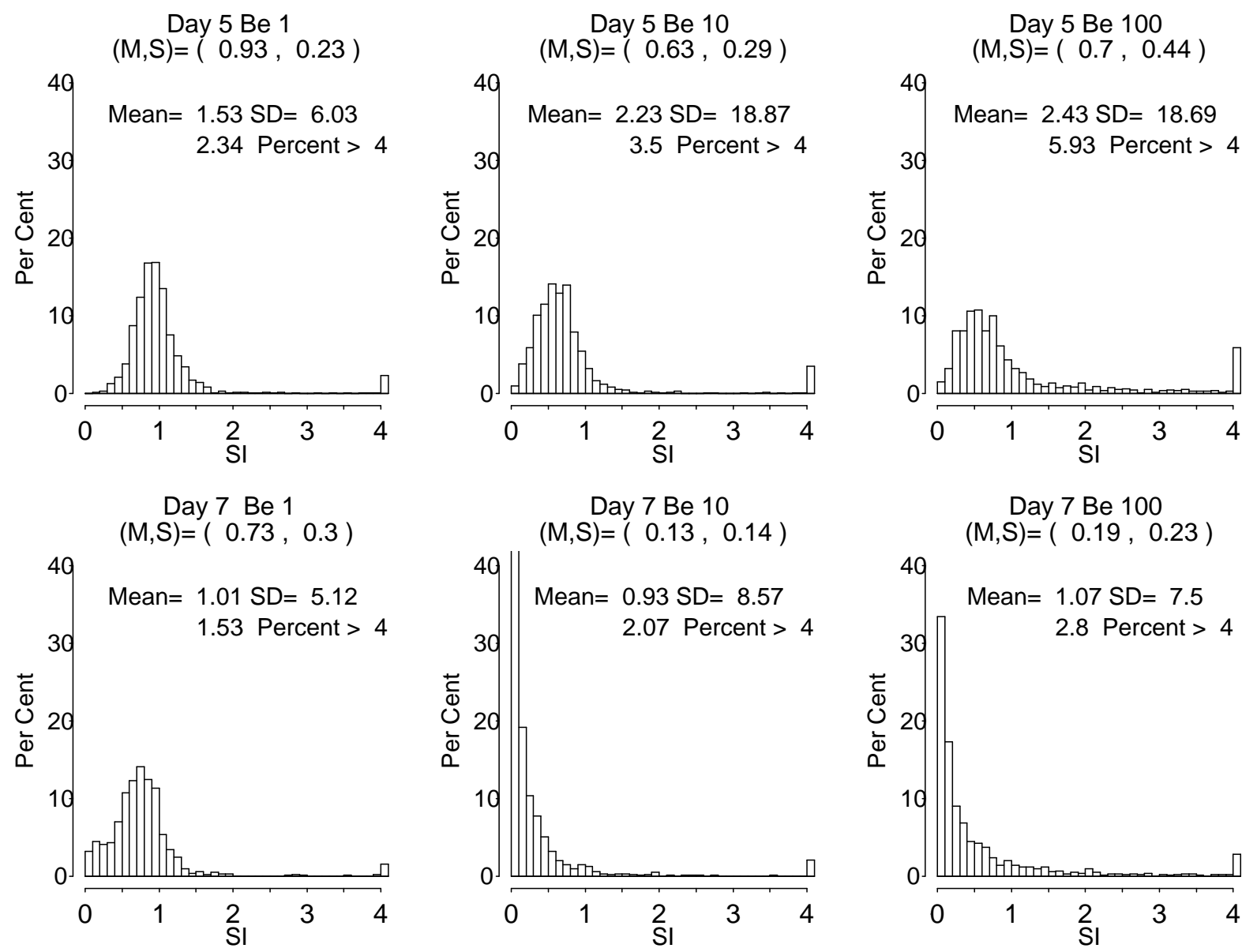

NOTE: $\mathrm{M}$ is Median SI and S is MAD estimate of Scale for SIs

Fig. 3. Histograms of the SIs for the beryllium workers and nonexposed BeLPTs. Numbers in parenthesis are the outlier restiant median(M) estimate of location and S the MAD estimate of the scale parameter. The mean and standard deviation (SD) for each distribution are also given. 
BeLPTs For 1080 Beryllium Workers and 33 Nonexposed

Sls Less Than 0.03125 Replaced with 0.03125 Sls Greater Than 4 Replaced with 4
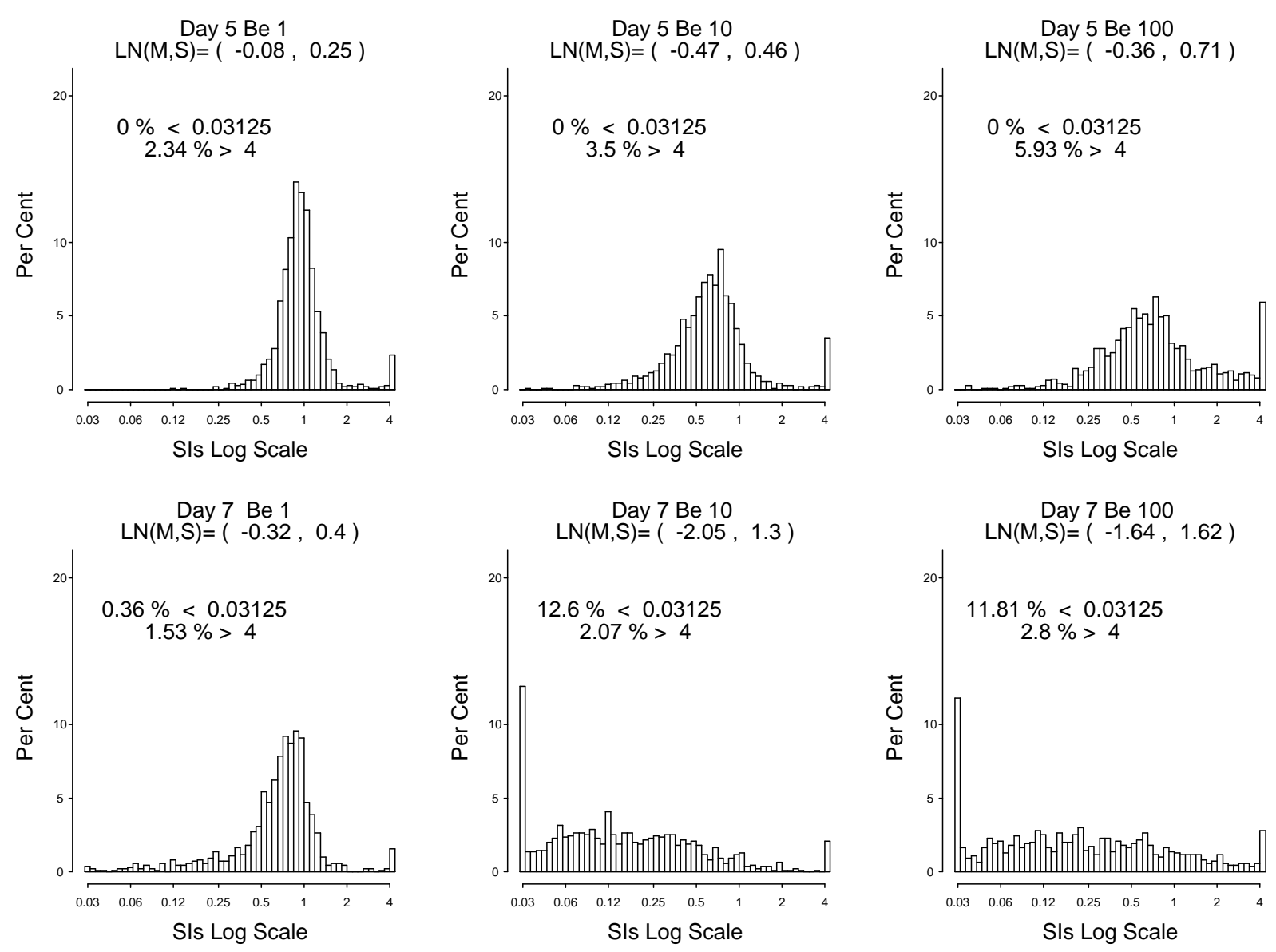

NOTE: $M$ is median $\operatorname{Ln}(\mathrm{SI}) \mathrm{S}$ is MAD estimate of Scale for $\mathrm{Ln}(\mathrm{SI})$

Fig. 4. Histograms of the $\operatorname{Ln}(\mathrm{SI}) \mathrm{s}$ for the beryllium workers and nonexposeds BeLPTs. The outlier restiant estimates on the Ln scale of location M (the median) and S the MAD estimate of the scale parameter for each distribution are given in parenthesis. 


\section{Y-12 Be Study: Gaussian Probability Plots (Log SIs) For Nonexposed and Beryllium Workers}

Day 5 Be 1

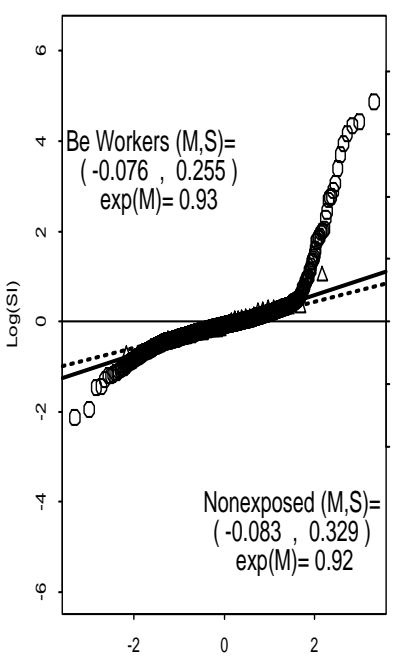

Day 7 Be 1

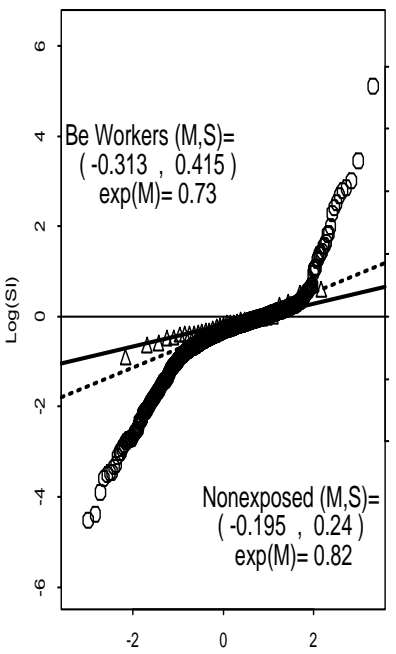

Day 5 Be 10

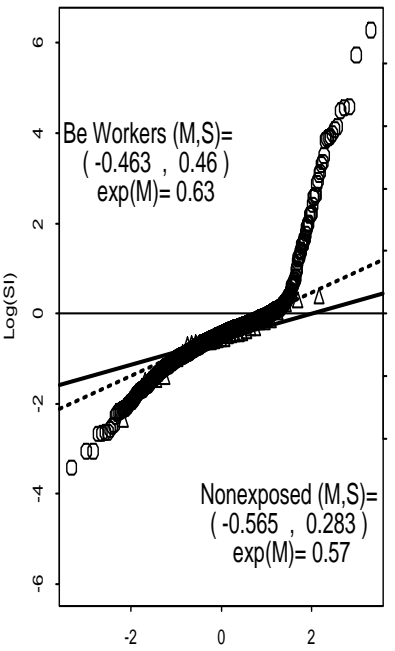

Day 7 Be 10

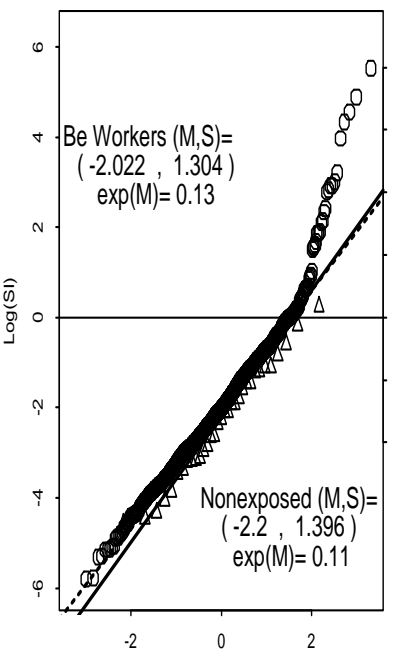

Day 5 Be 100

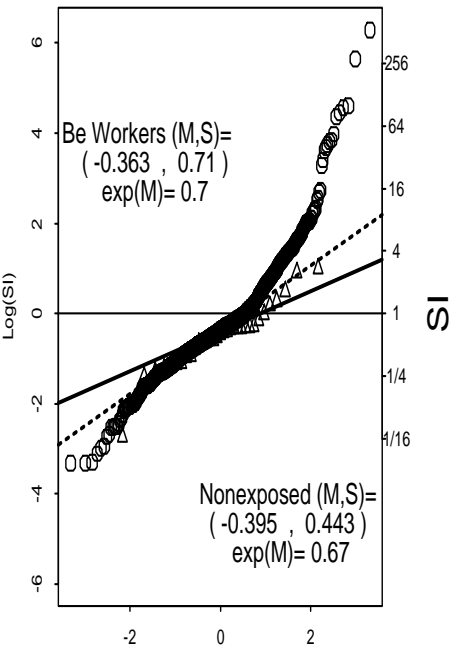

Day 7 Be 100

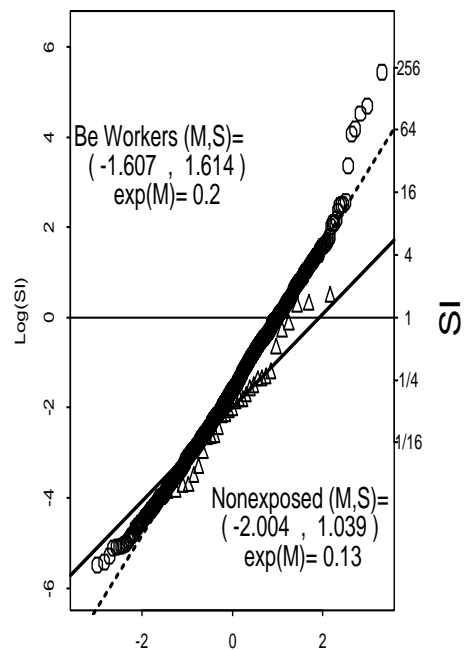

\section{Note: $M=\operatorname{Median}[\log (S I)] \quad S=S-M a d[\log (S I)]$}

Fig. 5. Normal q-q plots of $\operatorname{Ln}(\mathrm{si})$ s for each beryllium concentration on day 5 and day $\mathbf{7}$ for beryllium workers and nonexposed controls. The data values are shown on the vertical axis. The median (M), MAD scale estimate(S) of the $\operatorname{Ln}(\mathrm{si}) \mathrm{s}$ and $\exp (\mathrm{M})$ are listed on each plot. Values of $M$ and $S$ for beryllium workers (circles) are in upper left and nonexposed controls (triangles) are in lower right of each panel. 
Y-12 Beryllium Workers Study: Results For MAXIMUM SI

NOTE:SIs Less Than 0.25 Replaced with 0.25 SIs Greater Than 4 Replaced with 4
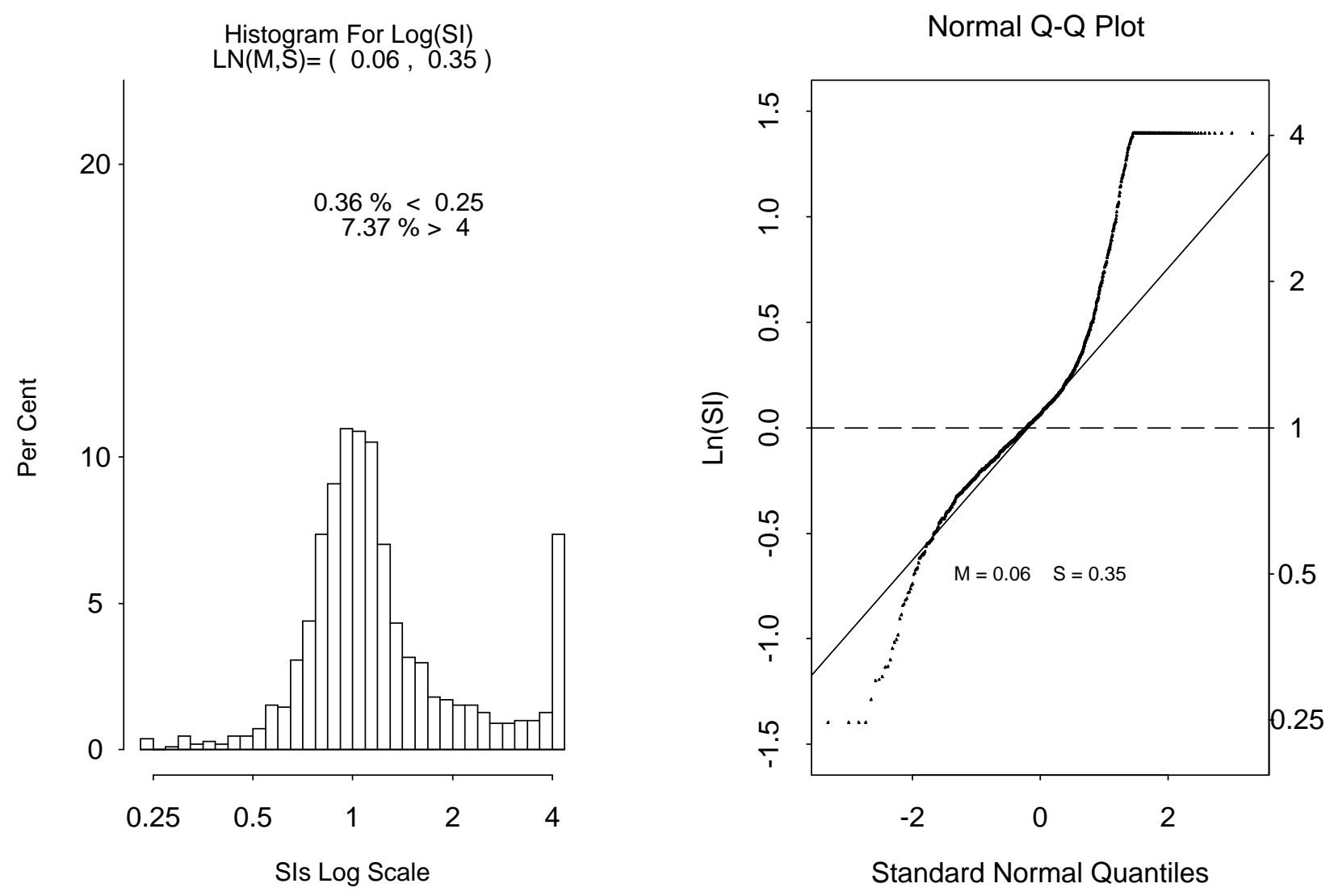

Fig. 6. Histogram and Normal Q-Q Plots for Ln(SImax) for beryllium workers and nonexposed combined. The Median (M), and MAD scale estimate(S) of the $\operatorname{Ln}(\mathrm{SI}) \mathrm{s}$ are shown. 
SImax for BeLPTs: Beryllium Workers (1080) Nonexposed(33)
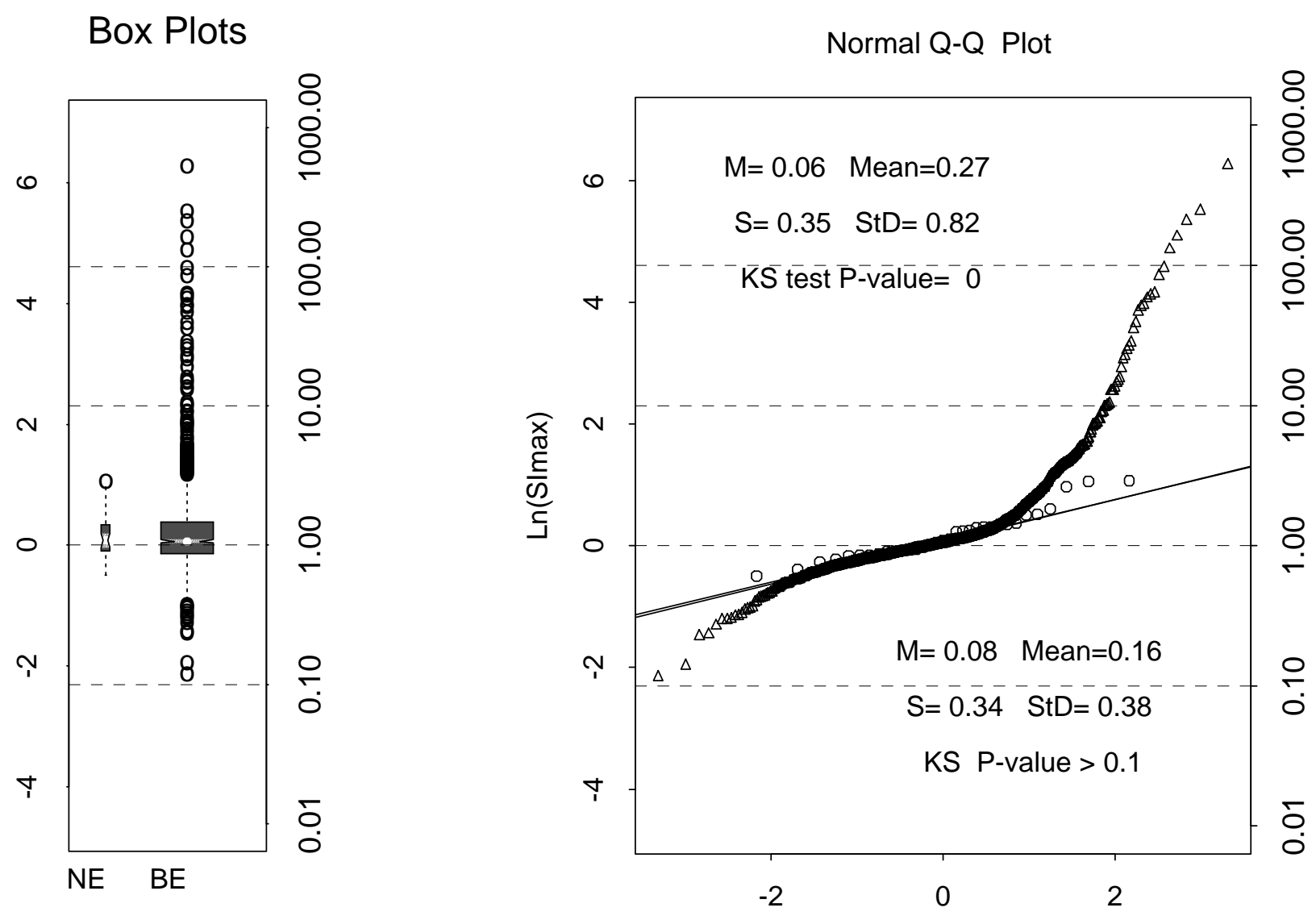

Standard Normal Quantiles

Fig. 7. Boxplots (left panel) and normal q-q plots (right panel) for $\operatorname{Ln}(\operatorname{SImax})$. In the right panel summary statistics for nonexposed controls (circles) are shown in lower right, and for beryllium workers (triangles) in upper left of q-q plot. A small P value for Kolmogorov-Smirnov (KS) goodness-of-fit test indicates departure from normal distribution for LN(SImax). 
Y-12 Study: Empirical ROC Curves For Ln(SI)s

Day 5 Be $1 \quad A U C=0.869$

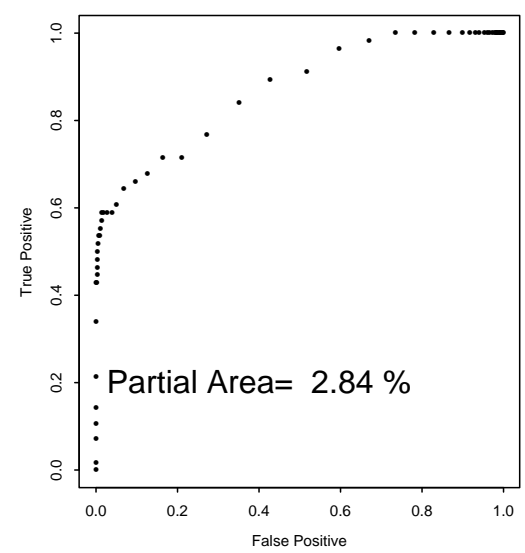

Day 5 Be $10 \quad A \cup C=0.934$

Day 5 Be $100 \quad A U C=0.943$
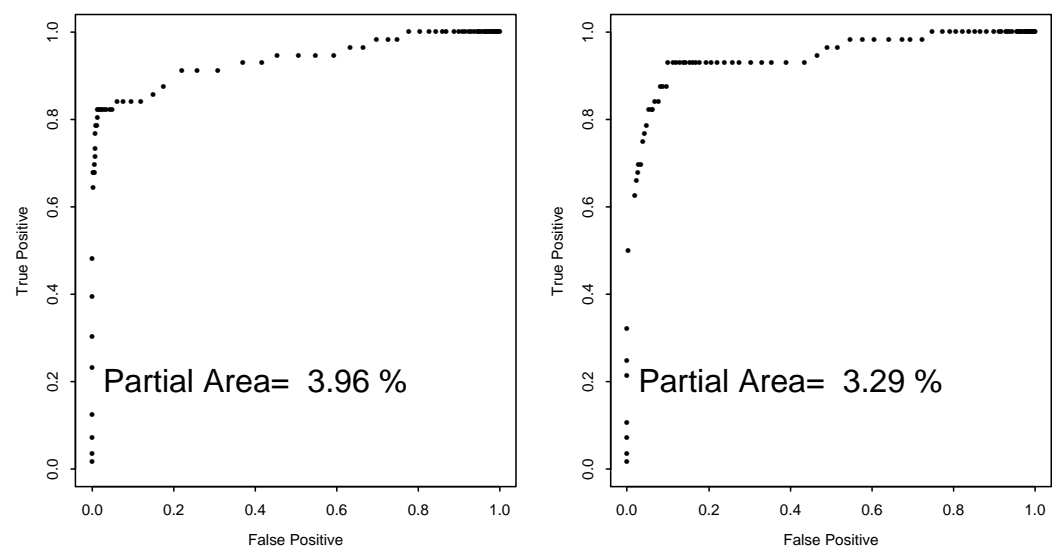

Day $7 \mathrm{Be} 1 \quad \mathrm{AUC}=0.82$

Day $7 \mathrm{Be} 10 \quad \mathrm{AUC}=0.889$

Day 7 Be $100 \quad A U C=0.896$
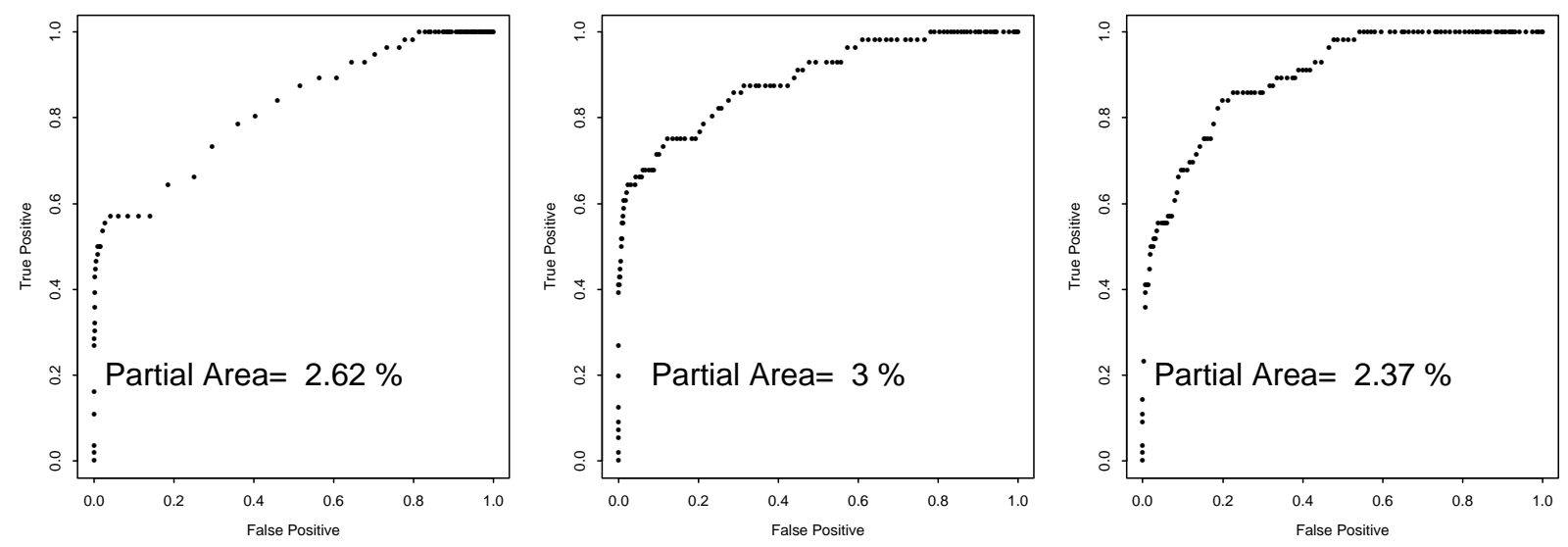

Note: $\mathrm{AUC}=$ Area Under ROC $\underset{\text { roc5t6.f }}{\text { Curve }}$ Partial Area is Over $(0,0.05)$

Fig. 8. Empirical ROC curves for $\mathrm{Ln}(\mathrm{SI}) \mathrm{s}$ for Each Beryllium Concentration on Day 5 and Day 7. AUC is the area under the curve. The partial AUC shown in each plot is based on a nonpametric estimate of the area under the ROC curve from 0 to 0.05 on the $x$-axis (i.e., maximum FPR of practial interest is 0.05 ). 


\section{ACKNOWLEDGMENTS}

This research was supported by the Offices of Occupational Medicine, Environment, Safety and Health, of the U. S. Department of Energy under contract DE-AC05-00OR22725 with UT-Battele, LLC. The authors thank ORISE, Center for Epidemiologic Research and ORNL, Computer Science and Mathematics Division staff for assistance in preparing this report.

The work has been authored by a contractor of the U.S. Government. Accordingly, the U.S. Government retains a nonexclusive, royalty-free license to publish or reproduce the published form of this work, or to allow others to do so for U. S. Government purposes.

\section{References}

[1] G. Basset, Jr. and R. Koenker. Asymptotic theory of least absolute error regression. Journal of the American Statistical Association, 73:618-622, 1978.

[2] J.M. Chambers, W.S. Cleveland, B. Kleiner, and P.A. Tukey. Graphical Methods for Data Analysis. Duxbury Press, Boston, 1983.

[3] D.L Cragle and W. G. Tankersley. Examination of workplace characteristics of workers sensitized to beryllium at the Y-12 plant. Technical report. To be published at Oak Ridge Institute for Science and Education.

[4] E.L. Frome and D.L. Cragle, editors. BeLPT-NB:Notes Concerning The Tritiated Thymidine Beryllium Lymphocyte Proliferation Test at http://www.csm.ornl.gov/ frome/BE/tnote.html. Oak Ridge National Laboratory, Oak Ridge, TN, 2001.

[5] E.L. Frome, D.L. Cragle, S.P. Colyer, and P.F. Wambach. Development and evaluation of a screening test for beryllium sensitization. In Proceedings of the Statistics in Epidemiology Section, Alexandria, VA, 2001. American Statistical Association.

[6] E.L. Frome, L.S. Newman, and M.M. Morz. Results of the analysis of the blood lymphocyte proliferation test data from The National Jewish Center,1997. Technical Report ORNL/TM-13338, Oak Ridge National Laboratory, 1997.

[7] E.L. Frome, M.H. Smith, L.G. Littlefield, R.L. Neubert, and S.P. Colyer. Statistical methods for the blood beryllium lymphocyte proliferation test. Environmental Health Perspectives Supplement, 104:957-968, 1996. 
[8] A. Geist and N. Nachtigal. Oak Ridge National Laboratory Electronic Notebook Project at

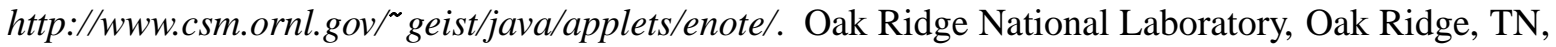
2000.

[9] J.M. Hanifin, W.L. Epstein, and M.J. Cline. In vitro studies of granulomatous hypersensitivity to beryllium. Journal of Investigative Dermatology, 55:284-288, 1970.

[10] H.L. Hardy and J.R. Tabershaw. Delayed chemical pneumonitis occuring in workers exposed to beryllium compounds. Indust. Hygine Toxicol., 28:197-211, 1946.

[11] S. Kotz and N.L Johnson. Encyclopedia of Statistical Science, Vol 8. John Wiley \& Sons, New York, NY, 1988.

[12] K. Kreiss, F. Miller, , L.S. Newman, A. Oj0-Amaize, M. Rossman, and C. Saltini. Chronic beryllium disease - from the workplace to cellular immunology, molecular immunogenetics, and back. Clinical Immunology and Immunopathology, 71:123-129, 1994.

[13] K. Kreiss, M.M. Mroz, B. Zhen, J.W. Martyny, and L.S. Newman. Epidemiology of beryllium sensitization and disease in nuclear workers. American Review of Respiratory Disease, 148:985-991, 1993.

[14] K. Kreiss, L.S. Newman, M.M. Mroz, and P.A. Campbell. Screening blood test identifies subclinical beryllium disease. Journal of Occupational Medicine, 31:603-608, 1989.

[15] C. J. Lloyd. Using smoothed receiver operating characteristic curves to summarize and compare diagnostic systems. Journal of the American Statistical Association, 93:1356-1364, 1998.

[16] P. McCullagh and J.A. Nelder. Generalized Linear Models. Chapman and Hall, London, 1989.

[17] L.S. Newman. Beryllium disease and sarcoidosis: clinical and laboratory links. Sarcoidosis, 1996.

[18] L.S. Newman. Significance of the blood beryllium lymphocyte proliferation test (BeLPT). Environmental Health Perspectives Supplement, 104:953-956, 1996.

[19] M. S. Pepe. Three approaches to regression analysis of receiver operating characteristic curves for continuous test results. Biometrics, 54:124-135, 1998.

[20] J. Sterner and M. Eisenbud. Epidemiology of beryllium intoxication. Arch. Ind. Hyg. Occup. Med., 4:123-157, 1951. 
[21] R.F. Stokes and M.D. Rossman. Blood cell proliferation response to beryllium: Analysis by receiveroperating characteristics. Journal of Occupational Medicine, 33:23-28, 1991.

[22] J.A. Swets and R.M. Pickett. Evaluation of Diagnostic Systems:Methods from Signal Detection Theory. Academic Press, New York, NY, 1982.

[23] L. Tornquist, P. Vartia, and Y. Vartia. How should relative changes be measured? The American Statistician, 39:43-46, 1985.

[24] P Wambach, editor. DOE-SPEC-1142-2001:BERYLLIUM LYMPHOCYTE PROLIFERATION TESTING at http://tis.eh.doe.gov/techstds/standard/spec1142/SPEC11422001.pdf. U.S. Department of Energy, Washington, D.C., 2001.

[25] H.K. Zou and X. A. Zhou. Receiver operating characteristic (ROC) analysis. Statistics in Epidemiology Newsletter at http://www.csm.ornl.gov/asasie/newsletter/SIEv2001n1.pdf, 2001. 


\section{A APPENDIX}

\section{A.1 LEAST ABSOLUTE VALUES ANALYSIS FOR BELPT}

The main results from Frome et al. [7] are summarized here. Let $y_{j k}$ denote the well count (see Exhibit A1) for the $k^{\text {th }}$ replicate of the $j^{t h}$ set of culture conditions (see Column 1 Exhibit A1). The data in Exhibit A1 are the raw counts for worker ID=271 and are used here to demonstrate the calculations.

\begin{tabular}{rrrrr} 
Treatment & \multicolumn{5}{c}{ Well Counts } \\
day5 controls & 1220 & 2391 & 1774 & 947 \\
day5 controls & 1499 & 1568 & 1410 & 1131 \\
day5 controls & 969 & 2265 & 1743 & 728 \\
day5 be1 & 1777 & 1890 & 1702 & 1885 \\
day5 be10 & 3368 & 7221 & 1473 & 3097 \\
day5 be100 & 3631 & 3655 & 2452 & 1634 \\
day7 controls & 3616 & 17410 & 3989 & 3144 \\
day7 controls & 669 & 1257 & 1497 & 4460 \\
day7 controls & 2897 & 4174 & 1366 & 1152 \\
day7 be1 & 1670 & 2186 & 629 & 1264 \\
day7 be10 & 330 & 598 & 254 & 264 \\
day7 be100 & 3611 & 4436 & 14452 & 14892 \\
PHA & 102160 & 44223 & 59344 & 51088 \\
CONA & 115673 & 104146 & 252237 & 159421
\end{tabular}

\section{Exhibit A1. Well Counts For BeLPT Assay 271}

The expected count in each well can be represented by a log-linear regression function:

$$
E\left(y_{j k}\right)=\lambda_{j}=\exp \left(X_{j} \beta\right)
$$

where $j=1, \ldots, 10$ and $k=1, \ldots, 12$ for the controls and $k=1,2,3,4$ for the beryllium stimulated cells and the positive controls (see column 1 of Exhibit A1). In equation (1), $X_{j}$ is a row vector of indicator variables and $\beta$ is the vector of regression parameters (see below). It is further assumed that the variance of the well counts is proportional to the square of the expected count, i.e. the standard deviation is proportional to the mean:

$$
\operatorname{Var}\left(y_{j k}\right)=\left(\phi \lambda_{j}\right)^{2}
$$

Equations 1 and 2 together are referred to as a generalized linear model with constant coefficient of variation $\phi$ (see McCullagh and Nelder [16, chap. 8] ). 
1) The first step in the LAV analysis is to take the Ln of the counts in Exhibit A1 (see Columns 2-4 of Exhibit A2). This is the variance-stabilizing transformation and leads to a linear model in say $z_{j k}=\ln \left(y_{j k}\right)$, with $\operatorname{Var}\left(z_{j k}\right) \simeq \phi^{2}$. The Ln of the counts are shown in columns 2-5 of Exhibit A2. If outliers are not present, applying ordinary least squares to the transformed data will yield consistent estimates for the $\operatorname{Ln}(\mathrm{SI})$ parameters [16]. The effect of outliers is minimized by using least absolute values (or some other robust method) on the $z_{j k}$.

2.) The second step is to calculate the median of the Ln counts for each Treatment Group. Let $\tilde{z}_{j}$ denote the median for the $j^{t h}$ beryllium concentration and $\tilde{z}_{o}$ denote the median of the Ln well counts for the corresponding control wells (see Column 6 of Exhibit A2).

3.) Step three is to calculate the $\mathbf{L A V}$ estimate of the $j^{t h} \mathbf{L n}(\mathbf{S I}), \tilde{\beta}_{j}=\tilde{z}_{j}-\tilde{z}_{o}$. For example, on Day $5 \mathrm{Be} 100$ the $\operatorname{Ln}(\mathrm{SI})=8.0010-7.2819=0.7191$, and the estimate of the $\mathrm{SI}$ is $\exp (0.7191)=2.05$.

\begin{tabular}{rrrrrr}
$\begin{array}{c}\text { Treatment } \\
\text { Group }\end{array}$ & \multicolumn{3}{c}{ Ln(well counts) } & Median \\
day5 controls & 7.1066 & 7.7795 & 7.4810 & 6.8533 & 7.2819 \\
day5 controls & 7.3126 & 7.3576 & 7.2513 & 7.0309 & 7.2819 \\
day5 controls & 6.8763 & 7.7253 & 7.4634 & 6.5903 & 7.2819 \\
day5 be1 & 7.4827 & 7.5443 & 7.4396 & 7.5417 & 7.5122 \\
day5 be10 & 8.1221 & 8.8847 & 7.2951 & 8.0382 & 8.0801 \\
day5 be100 & 8.1973 & 8.2039 & 7.8047 & 7.3988 & 8.0010 \\
day7 controls & 8.1931 & 9.7648 & 8.2913 & 8.0533 & 8.0123 \\
day7 controls & 6.5058 & 7.1365 & 7.3112 & 8.4029 & 8.0123 \\
day7 controls & 7.9714 & 8.3366 & 7.2196 & 7.0493 & 8.0123 \\
day7 be1 & 7.4206 & 7.6898 & 6.4441 & 7.1420 & 7.2813 \\
day7 be10 & 5.7991 & 6.3936 & 5.5373 & 5.5759 & 5.6875 \\
day7 be100 & 8.1917 & 8.3975 & 9.5786 & 9.6086 & 8.9880 \\
PHA & 11.5343 & 10.6970 & 10.9911 & 10.8413 & 10.9162 \\
C0NA & 11.6585 & 11.5535 & 12.4381 & 11.9793 & 11.8189
\end{tabular}

\section{Exhibit A2. Ln of Well Counts For BeLPT Assay ORISE ID= 271}

4.) The fourth step is to calculate the standard error of each $\operatorname{Ln}(\mathbf{S I})$. This requires an estimate of $\phi$ the standard deviation of the Ln counts (corresponds to CV on original scale). An outlier resistant estimatesee Frome et al. p. 959 [7]— "phitilde" of $\phi$ is $\tilde{\phi}=1.48 \times \sqrt{n /(n-p)} \times \operatorname{median}\left\{\left|z_{j k}-\tilde{z}_{j}\right|\right\}$. Estimates of $\phi$ are calculated for Day 5 and Day 7 , since it has been observed that there is generally more variability on Day 7. The estimated standard error of $\operatorname{Ln}(\mathrm{SI})$ is $\operatorname{StErr}=\tilde{\phi} \sqrt{\operatorname{diag}(V)}$, where $V=(\pi / 2)\left(X^{\prime} X\right)^{-1}$. Using Day 5 as an example, the residuals $u_{j k}=z_{j k}-\tilde{z}_{j}$ are shown in Exhibit A3, and $\tilde{\phi}=1.48 \times \sqrt{24 / 20} \times(0.1963)=$ 0.3183 , where median $\left|z_{j k}-\tilde{z}_{j}\right|=0.1963$. The standard error of Day $5 \operatorname{Ln}(\operatorname{SI})$ 's is $\operatorname{StErr}=\tilde{\phi} \sqrt{\operatorname{diag}(V)}=$ $0.3183 \times \sqrt{1.571 \times 0.25}=0.230$. 
5.) Divide the $\operatorname{Ln}(\mathrm{SI})$ by its standard error to obtain the standardized $\operatorname{Ln}(\mathrm{SI})$. Dividing each $\operatorname{Ln}(\mathrm{SI})$ by its standard error results in a statistic that is in "standard measure," having mean 0 and standard deviation 1 (see Kotz, S. and Johnson, p. 631 [11]). The LAV estimate of the standardized Ln(SI) For Day 5 Be100 is $\mathrm{SLsi}=\operatorname{Ln}(\mathrm{SI}) / \mathrm{StErr}[\operatorname{Ln}(\mathrm{SI})]=0.7197 / 0.230=3.13$. If outliers are not present, and the $z_{j k} s$ are normally distributed, then the least squares estimate of the $j \operatorname{th} \operatorname{Ln}(\mathrm{SI})=\hat{\beta}_{j}=\hat{z}_{j}-\hat{z}_{o}$, i.e. the treatment effects on the Ln scale. Here $\hat{z}_{j}$ denote the mean for the $j^{\text {th }}$ beryllium concentration and $\hat{z}_{o}$ denote the mean of the $\mathrm{Ln}$ well counts for the corresponding control wells, i.e. these are the "least squares" estimates of location and scale. Under the null hypothesis of no treatment effect, $H_{o}: \beta_{j}=0$, dividing the $\operatorname{Ln}(\mathrm{SI})$ by its standard error results in a standardized $\operatorname{Ln}(\mathrm{SI})$ that will follow Student's $t$ distribution with $n-p$ degrees of freedom (df). The LAV estimates are asymptotically Gaussian with covariance matrix $\phi V$-see Basset and Koenker [1]. In large samples the outlier resistant standardized $\operatorname{Ln}(\mathrm{SI})$ will follow the standard normal distribution. The small sample distribution of the outlier resistant $\mathrm{Ln}(\mathrm{SI})$ is not know. For this application we will use the appropriate $\mathrm{t}$-distribution (with $\mathrm{df}=20$ ) as a reference distribution to identify a large value for this test statistic. The critical value or "cut point" of 2.53 is selected so that under $H_{o}$ the probability that the SLsi exceeds 2.53 is approximately 1 percent. For a BeLPT assay to be called "abnormal" at least two SLsis must exceed this value, so the statistical false positive probability that a normal test is called abnormal is about 0.1 percent.

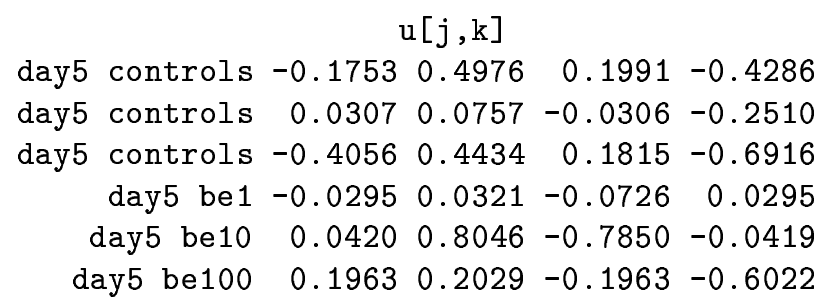

Exhibit A3. Residuals From Day 5 in Exhibit A2 


\section{A.2 SUMMARY LAV REPORT FOR THE BELPT}

The results of all of the calculations and additional statistics are combined into a single laboratory LAV report (see Exhibit A4). Note that "CV-mad" (this is the resistant estimate $\tilde{\phi}$ for each treatment group) and the residuals in the Panel I of Exhibit A4 have been multiplied by 100, i.e., they are in Log percent units (L\%) - see Tornquist et al. [23]. For example the first residual for the Day 5 control wells is $100 \times$ $\operatorname{Ln}(1220 / 1453.8)=-18 L \%$. Panel II of Exhibit A4 lists the LAV estimates of the SIs, Ln(SI)s and SLsi for each beryllium concentration on day 5 and Day 7 and the positive controls. The estimates of $\tilde{\phi}$ for the control wells and treated wells for Day 5 and Day 7 with and without "pooling" are provided in the Panel III of Exhibit A4. An "overall" pooled estimate is also provided. These values are used to calculate the standard error[ $[\mathrm{Ln}(\mathrm{SI})]$ and to evaluate the amount of variation within control and treated groups on Day 5 and Day 7.

The LAV report is used for quality control (e.g. to identify unacceptable tests) and to help in the interpretation of acceptable BeLPTs that are not confirmed abnormals or normals. The BeLPT in Exhibit A4 has two large standardized SLsis (D5be10 and D5be100) indicating a statistical positive test (see Item 1 Section 2.3 ). The standardized Ln(MaxSI) for this test, (see Section 2.3 Item 2) is $\mathrm{Zmax}=(0.98-\mathrm{M}) / \mathrm{S}$ $=(0.98-0.081) / 0.34=2.64$. This is below the cut point of 3.1 (see Section 2.3) for the reference data set. The values of $\tilde{\phi}$ are high on Day 7 and the standardized $\operatorname{Ln}(\mathrm{SI})$ for D7be10 is -3.98, indicating cell killing in at least one well. Based on the criteria in Section 2.3 this is a borderline test and was also interpreted as borderline by the ORISE LPT laboratory using the criteria describe in Section 3.4. Subsequent testing found this patient to be SENSITIZED. 


\begin{tabular}{|c|c|c|c|c|c|c|c|c|c|c|}
\hline Treatment Grp & & Well & 1 Counts & & & & Res: & idua & & \\
\hline & & & & & FIT* & CV-mad & & & & \\
\hline ay5 controls & 1220 & 2391 & 1774 & 947 & 1453.8 & 34.9 & -18 & 50 & 20 & -43 \\
\hline ay5 controls & 1499 & 1568 & 1410 & 1131 & 453.8 & 34.9 & 3 & 8 & -3 & -25 \\
\hline ay5 controls & 969 & 2265 & 1743 & 728 & 1453.8 & 34.9 & -41 & 44 & 18 & -69 \\
\hline day 5 be 1 & 1777 & 1890 & 170 & 1885 & 1830.2 & 5.3 & - & 3 & -7 & \\
\hline day5 be 10 & 3368 & 7221 & 147 & 3097 & 3229.7 & 70.8 & \pm & 80 & -79 & -2 \\
\hline day5 b & 3631 & 365 & 24 & 1634 & 2983.8 & 34.2 & 20 & 20 & -20 & -60 \\
\hline ay7 controls & 3616 & 1741 & 3989 & 3144 & & 84.5 & 18 & 175 & 28 & \\
\hline ay7 controls & 669 & 1257 & 1497 & 4460 & & 84.5 & -151 & -88 & -70 & $3 \varsigma$ \\
\hline ay7 controls & 2897 & $41^{\circ}$ & 1366 & 1152 & & 84.5 & -4 & 32 & -79 & -96 \\
\hline day 7 be 1 & 1670 & 2186 & & 1264 & 2.9 & 46.9 & 14 & 41 & -84 & -14 \\
\hline day7 be10 & 330 & & & 264 & & 22.4 & 11 & 71 & -15 & -11 \\
\hline day7 be 100 & 3611 & 4436 & 14452 & 14892 & 8006.8 & 103.7 & -80 & -59 & 59 & 6 \\
\hline & 2156 & 44221 & 59346 & 51090 & 55063.5 & 25.2 & 62 & -22 & 7 & -7 \\
\hline CON & 5673 & 104146 & 252237 & 159421 & 135796.6 & 36.4 & -16 & -27 & 62 & \\
\hline
\end{tabular}

$*$ FIT $=$ Fitted Value $=\exp [\operatorname{median}(\log z)]$ for each treatment group NOTE: CV-mad and residuals are in $\mathrm{L} \%$ units

II- STIMULATION INDICES (SI)

\begin{tabular}{|c|c|c|c|c|c|c|c|c|}
\hline & & Day 5 & & & Day 7 & & Positve & Controls \\
\hline & D5be1 & D5be10 & D $5 \mathrm{be} 10$ & 0 D7be 1 & 1 D7be10 & D7be100 & $0 \quad$ PHA & A CONA \\
\hline SI & 1.26 & 2.22 & 2.05 & 0.48 & 0.10 & 2.65 & 37.88 & 93.41 \\
\hline LogSI & 0.23 & 0.80 & 0.72 & -0.73 & -2.32 & 0.98 & 3.63 & 4.54 \\
\hline SLsi & 1.00 & 3.48 & 3.13 & -1.25 & -3.98 & 1.67 & 15.83 & 19.76 \\
\hline
\end{tabular}

NOTE SLsi= LogSI/StERR is Standardized LogSI

Large POSITIVE value ( GT 2.5 ) Indicate POSTIVE Response

Large NEGATIVE value ( LT -2.5) Indicate Cell Killing

III- SUMMARY STATISTICS PHITILDE (Coefficient of Variation)*

$\begin{array}{llllll}\text { Overall: } & 0.385 & & & & \\ \text { Day } 5 \text { Control: } & 0.349 & \text { Day } 5 \text { Treated: } & 0.23 & \text { Day } 5 \text { Pooled: } & 0.319 \\ \text { Day } 7 \text { Control: } & 0.845 & \text { Day } 7 \text { Treated: } & 0.855 & \text { Day } 7 \text { Pooled: } & 0.811\end{array}$

* Phitilde is MAD estimate of the standard deviation on log scale (corresponds to $\mathrm{CV}$ on original scale)

Exhibit A4. LAV Report for BeLPT Assay 271 


\section{INTERNAL DISTRIBUTION}

1. E. L. Frome

2. C. K. Bayne

3. T. Zacharia
4. Central Research Library

5. ORNL Laboratory Records-RC

6-7. DOE Office of Scientific and Technical Information (OSTI)

\section{EXTERNAL DISTRIBUTION}

8. S. P. Colyer, Oak Ridge Institute for Science and Education, P. O. Box 117, Oak Ridge, TN 37831

9. D. L. Cragle, Oak Ridge Institute for Science and Education, P. O. Box 117, Oak Ridge, TN 37831

10. L. G. Littlefield, Oak Ridge Institute for Science and Education, P. O. Box 117, Oak Ridge, TN 37831

11. H. Stockwell, Epidemiology and Health Surveillance, EH-62 CC 270, U. S. Department of Energy, 19901 Germantown Road, Germantown, MD 20874

12. P. F. Wambach, Occupational Medicine, EH-61 CC 270, U. S. Department of Energy, 19901 Germantown Road, Germantown, MD 20874

13. E. White, Occupational Medicine, EH-61 CC 270, U. S. Department of Energy, 19901 Germantown Road, Germantown, MD 20874 